\title{
CIDADES NEGRAS NO BRASIL: TERRITÓRIOS E CIDADANIA
}

\author{
Reinaldo José de Oliveira ${ }^{1}$
}

Resumo: O texto em questão tem como objetivo a observação das Cidades Negras, aqui, interpretada pelas pequenas e médias cidades. Analiso como a segregação étnicoracial reflete nas pequenas e médias cidades do Brasil. No texto, selecionei e analisei, inicialmente, do universo das cem maiores cidades, proporcionalmente (\%), as dez maiores cidades com representação negra. Para entender as desigualdades e a segregação, analisei o rendimento nominal médio entre brancos e negros no Brasil e nas cidades selecionadas. Dentre as interpretações sobre o quadro das pequenas e médias cidades, as cidades negras estão localizadas no nordeste do país, nos estados de Maranhão e Bahia, sobretudo na Bahia, na região do Recôncavo. Em nossa atualidade, as cidades negras sofrem um impacto da segregação étnico racial diferente dos grandes centros, em razão de aspectos históricos e locais que são particulares ao território.

Palavras Chave: pequenas e médias cidades, segregação racial, desigualdades, planejamento urbano e racismo.

\section{BLACK CITIES IN BRAZIL: TERRITORIES AND CITIZENSHIP}

\begin{abstract}
The text in question aims to observe the Black Cities, here, interpreted by small and medium-sized cities. I analyze how racial ethnic segregation reflects in small and medium-sized cities in Brazil. In the text, I initially selected and analyzed the universe of the hundred largest cities, proportionally (\%), the ten largest cities with black representation. To understand inequalities and segregation, I analyzed the average nominal income between whites and blacks in Brazil and in selected cities. Among the interpretations of the picture of small and medium cities, black cities are located in the northeast of the country, in the states of Maranhão and Bahia, especially in Bahia, in the Recôncavo region. Nowadays, black cities suffer an impact of racial ethnic segregation different from large centers, due to historical and local aspects that are particular to the territory.
\end{abstract}

Keywords: small and medium cities, racial segregation, inequalities, urban planning and racism.

\section{CIUDADES NEGRAS EN BRASIL: TERRITORIOS Y CIUDADANÍA}

\footnotetext{
${ }^{1}$ Sociólogo, Professor Doutor do Centro de Formação de Professores CFP/UFRB. Docente do IFBA. Professor Colaborador do NEPPINS/CCS/UFRB. E-mail: reinaldo.jose@uol.com.br Orcid: https://orcid.org/0000-0003-3770-7862
} 


\title{
Otarandusen
}

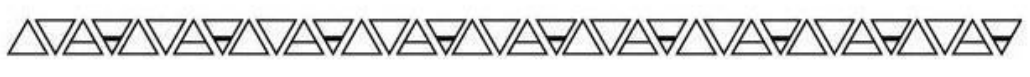

Resumen: El texto en cuestión apunta a observar las Ciudades Negras, aquí, interpretadas por ciudades pequeñas y medianas. Analizo cómo se refleja la segregación étnica racial en las ciudades pequeñas y medianas de Brasil. En el texto, inicialmente seleccioné y analicé el universo de las cien ciudades más grandes, proporcionalmente (\%), las diez ciudades más grandes con representación negra. Para comprender las desigualdades y la segregación, analicé el ingreso nominal promedio entre blancos y negros en Brasil y en ciudades seleccionadas. Entre las interpretaciones de la imagen de las ciudades pequeñas y medianas, las ciudades negras se encuentran en el noreste del país, en los estados de Maranhão y Bahía, especialmente en Bahía, en la región de Recôncavo. Hoy en día, las ciudades negras sufren un impacto de segregación étnica racial diferente de los grandes centros, debido a aspectos históricos y locales que son particulares del territorio.

Palabras clave: ciudades pequeñas y medianas, segregación racial, desigualdades, planificación urbana y racismo.

\section{VILLES NOIRES AU BRÉSIL: TERRITOIRES ET CITOYENNETÉ}

Résumé: Le texte en question vise à observer les Cités noires, ici, interprétées par les petites et moyennes villes. J'analyse la façon dont la ségrégation ethnique raciale se reflète dans les petites et moyennes villes du Brésil. Dans le texte, j'ai d'abord sélectionné et analysé l'univers des cent plus grandes villes, proportionnellement (\%), les dix plus grandes villes à représentation noire. Pour comprendre les inégalités et la ségrégation, j'ai analysé le revenu nominal moyen entre blancs et noirs au Brésil et dans certaines villes. Parmi les interprétations de l'image des petites et moyennes villes, les villes noires sont situées dans le nord-est du pays, dans les États de Maranhão et Bahia, notamment à Bahia, dans la région de Recôncavo. De nos jours, les villes noires subissent un impact de ségrégation ethnique raciale différent des grands centres, en raison d'aspects historiques et locaux propres au territoire.

Mots-clés: petites et moyennes villes, ségrégation raciale, inégalités, urbanisme et racisme.

\section{INTRODUÇÃO}

\author{
"A cor dessa cidade sou eu \\ O canto dessa cidade é meu \\ A cor dessa cidade sou eu \\ O canto dessa cidade é meu (...)"
}

Das 5.565 cidades brasileiras, há milhares de urbes que estão no quadro descrito na letra da música, cantada por Daniela Mercuy. Nossas cidades são diversas, múltiplas e ricas em valores étnicos raciais, no entanto, as populações vulneráveis, pobres e marginalizadas lutam por direitos, em especial, a população negra está presente em todo 
o território nacional, suas inscrições estão no território; a força de trabalho negra que perfez as bases do capitalismo nacional e internacional nos 388 anos da sociedade escravocrata e nos últimos 132 anos.

A geografia das desigualdades tem cor, está inscrita nas urbes do país, conforme o grau de ocupação no mercado de trabalho, no universo da habitação e no chão das cidades brasileiras.

No presente texto, analisarei as pequenas e médias cidades negras frente ao cenário das desigualdades e da segregação racial no Brasil. O racismo e a segregação são iguais ou diferentes nas urbes de pequeno, médio e grande porte nas cidades brasileiras? Acredito que cada cidade é particular, compreende uma leitura e interpretação específica, no entanto, o racismo se inscreveu em todo o território do país, ora está mais presente nas áreas mais desenvolvidas e urbanizadas e, ora se inscreve nos lugares e territórios que subsidiam o desenvolvimento do capital e da rede urbana, como as pequenas e médias cidades.

Das 5.565 urbes, analisei as que tem o maior número de população negra (pretos e pardos), de forma relativa (\%). Das cem maiores cidades, selecionei as dez primeiras urbes com maior participação de negros. Farei observações das desigualdades entre brancos e negros, tendo como interpretação dados estatísticos sobre rendimento do Censo Demográfico do IBGE, 2010.

Com o objetivo de trazer entendimentos, o texto está organizado com a seguinte estrutura: inicialmente, a interpretação teórica metodológica sobre pequenas e médias cidades, posteriormente, a ideia de cidades negras e, em seguida, parcialmente, o contexto histórico, social e cultural do Recôncavo, e as considerações finais, apresento que nas pequenas e médias cidades, prevalece as desigualdades e a segregação racial.

\section{PEQUENAS E MÉDIAS CIDADES NO BRASIL}

Faço aqui minha iniciação nos estudos e pesquisas sobre as pequenas e médias cidades brasileiras. Meus trabalhos (OLIVEIRA, 2018; 2017; 2016;2013), tem como observação as metrópoles e o cenário nacional, tendo como centralidade a geografia, os espaços sociais e os territórios étnico raciais. A partir da observação das pequenas e médias cidades, analisarei a segregação da população negra e o racismo. Me deparei 
com um campo de estudos e pesquisas incipiente por parte da literatura nacional e dos principais centros de estudos e pesquisas sobre a cidade e as relações étnico raciais.

No texto "Segregação Racial e Desigualdades Urbanas nas Cidades Brasileiras: Elementos para uma Observação da Necropolítica" (2020), observei o cenário das dez principais metrópoles, como São Paulo, Rio de Janeiro, Salvador, dentre outras, enquanto espaços e territórios que reúnem, de forma absoluta, as maiores proporções da população negra. Constatei que a sobrerepresentação socioeconômica está presente nas dez maiores urbes, nas 100 maiores cidades, portanto, o fenômeno é um quadro histórico e contemporâneo que caracteriza elementos da necropolítica e da política antinegro.

A necropolítica e a política antinegro reforçam o cenário, de forma objetiva e subjetiva, a massa negra no universo do desemprego, nos mapas de óbitos da pandemia da Covid-19, do homicídio e do feminicídio. Nos últimos 132 anos as políticas públicas universais refletiram no universo das cidades com os lugares negros fora das ideias e das ideias fora dos lugares negros (MARICATO, 2002).

Conforme a literatura sobre pequenas e médias cidades no Brasil, Maria Encarnação Beltrão Sposito (2009), Roberto Lobato Corrêa (2011) Maria F. Lopes (2010), Dolarice S.Maia (2010), Wendel Henrique (2009; 2010) e Jânio Santos (2010), todos compartilham das mesmas considerações, as cidades são diferentes uma das outras, são múltiplas e diversas, elas são urbanas, rurais, turísticas, industriais, comerciais, litorâneas, locais, regionais e globais, portanto, seguem critérios de ordem quantitativa e qualitativa e de forte conteúdo reflexivo sobre suas funções socioeconômica e política.

Maria Encarnação Beltrão Sposito (2009) explica que um dos pilares para pensar o cenário teórico conceitual sobre as pequenas e médias cidades, diz respeito a articulação entre o rural e o urbano. Para a autora, não há qualquer possibilidade de entender o contexto sem tratar dessa articulação do que se passa nesses dois espaços, o rural e o urbano.

Uma segunda característica problematizada pela autora, trata-se de buscar compreender cidades pequenas e médias por intermédio da relação entre a cidade e a região. O que há de configuração nessa relação entre cidade e a região? Conforme os comentários de Sposito, é no território das pequenas e médias cidades que se 
estabelecem as redes, diálogos, funções e a dinamização das principais forças que perfazem o ambiente construído, por exemplo, os complexos serviços nas áreas de saúde, educação de nível superior, transportes, atividades de fins econômicos e financeiro, formação de mão de obra voltada para o universo do meio técnico científico informacional e as inúmeras características que as urbes apresentam no país.

A cidade de Feira de Santana (BA) perfaz esta condição de cidade média. Esta urbe reúne o ambiente construído nas áreas de saúde, transportes, educação, alimentos, empregos e uma diversidade de produtos e ferramentas que as cidades da região e das cercanias precisam.

Para a autora, as cidades médias e pequenas são expressões da totalidade, mas não são representativas de toda a realidade. Para melhor entendimento das ideias, destaco que há cidades pequenas e médias que diante das grandes transformações do século XX, passaram por um processo rápido de urbanização e outras não.

Ermínia Maricato (2002) delimita que na realidade nacional há determinados lugares e territórios que não passam pela interpretação do pensamento urbanístico, como os loteamentos irregulares e os territórios de extrema pobreza e vulnerabilidade. Nas pequenas, médias e grandes cidades, a problematização em arquitetar ideias e lugares ou lugares e ideias, tem sido uma constante busca no cenário nacional.

Maricato (2002) e Sposito (2009) proporcionam com suas reflexões sobre a cidade e o urbano, independente das funções e papéis que elas desempenham, pensar a igualdade e a diferença no chão das pequenas, médias e grandes cidades. Acredito que este é um processo que irá depender de todos, dentre eles; dos pesquisadores, gestores e profissionais que observam a cidade e o urbano e dos movimentos sociais que lutam por espaços e territórios de direitos.

Segundo Doralice S. Maia (2010) é preciso compreender o quadro urbano, histórico e contemporâneo, principalmente as cidades médias e pequenas. A generalização da urbanização não pode ser referência para todas as urbes. No território nacional as cidades médias e pequenas são essenciais para estruturar políticas públicas e territoriais para o universo da população, mas é por isso que urge uma necessidade de problematizar as diferentes características das cidades.

$\mathrm{Na}$ interpretação de Maia (2010), a cidade média seria aquela que se contraporia à cidade grande. A urbe média seria aquela que está entre uma e outra, ou seja, em uma 
dimensão intermediária de cidades. Outra importante característica, a autora destaca que as cidades pequenas são aquelas que possuem até 20 mil habitantes, acima deste montante são classificadas como cidades médias e aquelas com mais de 500 mil são consideradas grandes. A demografia e os estudos da população tem sido um critério adotado pelas instituições de estudos estatísticos para melhor observar as urbes brasileiras e suas classificações.

É importante considerar que uma cidade com 100 mil habitantes das regiões norte ou nordeste é diferente de uma cidade da região sudeste, portanto, o tamanho da demografia e da área física precisa vir acompanhado de um conteúdo representativo, de informações consistentes, como a força e o peso dos capitais econômico, social, político, cultural e tecnológico.

A noção de cidades médias corresponde às cidades que apresentam uma concentração e centralização econômicas expressivas, provocadas pela confluência do sistema de transporte, podendo ser reconfigurada pela incorporação de novas atividades do setor agropecuário que, por sua vez, redefinem a indústria, o comércio e os serviços. A intermediação dos papéis e funções socioeconômicas e as relações entre cidade e campo, fazem parte das considerações conceituais para o entendimento de cidades médias e pequenas.

Nas próximas páginas, destaco as cidades médias e pequenas sobrerepresentadas por habitantes negros. Um questionamento é válido para compor as reflexões que perfazem a ideia de cidades médias e pequenas no cenário nacional: a geografia das cores entre brancos e negros pode definir os melhores lugares e as oportunidades nas cidades do país?

\section{CIDADES NEGRAS}

$\mathrm{Na}$ geografia das cidades brasileiras, existem particularidades que merecem ser obaservadas, por exemplo, o chão dos territórios e territorialidades compreendem diferenças étnico raciais que retratam aspectos socioeconômicos, culturais e políticos, sobretudo observações que correspondem ao quadro da necropolítica e da política antinegro. 
Sem nenhuma dúvida, as grandes cidades refletem na estrutura e na composição das pequenas e médias cidades, como, por exemplo, o planejamento urbano define a ocupação dos territórios e a geografia das desigualdades étnico raciais. Nas pequenas e médias cidades, o planejamento urbano está alinhado ao processo de produção social do espaço que vêm favorecendo setores de maior poder aquisitivo, em sua maioria brancos (SANTOS, 1997).

As cidades da tabela 1 abaixo, das dez urbes, duas estão localizadas no estado de Maranhão e oito estão localizadas no estado da Bahia, sobretudo na região do Recôncavo Baiano ${ }^{2}$.

Conforme os dados da tabela 1 abaixo, a participação da população negra na geografia das cidades brasileiras, está diretamente relacionado ao passado e ao contexto atual. Nos 388 anos de sociedade escravocrata, a força de trabalho de africanos e afrobrasileiros constituiu as bases do desenvolvimento da sociedade.

De 1549 até 1763, a cidade de Salvador assumiu o posto da primeira capital do país. Salvador e a região do Recôncavo Baiano, juntas, reuniram o maior número de escravizados em todo o território brasileiro na época da colonização (REIS, 2003).

Tabela 1. Distribuição da População Brasileira classificada por cor raça, em dados relativos, 2010

\begin{tabular}{|c|c|c|c|c|}
\hline Brasil e Município & $\begin{array}{c}\text { Branca } \\
\%\end{array}$ & $\begin{array}{c}\text { Negro } \\
\%\end{array}$ & $\begin{array}{c}\text { Branca } \\
\%\end{array}$ & $\begin{array}{c}\text { Negro } \\
\%\end{array}$ \\
\hline Brasil & 53,74 & 44,57 & 47,50 & 50,94 \\
\hline Serrano do Maranhão (MA) & 3,3 & 94,05 & 5,05 & 93,35 \\
\hline Pedrão (BA) & 8,06 & 91,81 & 5,59 & 92,83 \\
\hline São Gonçalo dos Campos (BA) & 8,97 & 89,61 & 6,7 & 92,47 \\
\hline Antônio Cardoso (BA) & 10,14 & 88,71 & 7,04 & 92,21 \\
\hline Bacurituba (MA) & 14,89 & 81,41 & 6,11 & 92,16 \\
\hline São Francisco do Conde (BA) & 8,83 & 90,33 & 5,93 & 91,86 \\
\hline Aramari (BA) & 6,9 & 90,03 & 7,12 & 91,71 \\
\hline Conceição da Feira (BA) & 10,99 & 86,32 & 7,17 & 91,61 \\
\hline Irará (BA) & 9,68 & 89,53 & 7,03 & 91,3 \\
\hline
\end{tabular}

\footnotetext{
${ }^{2}$ Outra leitura importante, realizei a seleção das cem maiores urbes com participação negra (\%), sessenta e oitos estão localizadas no Estado da Bahia, no território que compreende a capital, a Região Metropolitana, o Recôncavo e a região de Feira de Santana. Em razão da organização do texto (como o conteúdo e a literatura abordada) e das regras delimitando o número de páginas, não foi possível disponibilizar a relação com as cem cidades negras, em dados proporcionais (\%).
} 


\begin{tabular}{|c|c|c|c|c|}
\hline Amélia Rodrigues (BA) & 9,13 & 89,01 & 8,18 & 91,16 \\
\hline
\end{tabular}

Fonte: Banco SIDRA, Censo Demográfico do IBGE, 2000/2010.

Durante o setecentismo até os últimos anos da capital do Brasil, a cidade de Salvador ocupava o primeiro lugar entre todos os portos de Portugal ultramarino. No final do século XVIII, a capital da Bahia contava com mais de 60 mil pessoas em seu território, em sua grande maioria, era constituída por africanos e afro-brasileiros. Lucilene Reginaldo (2011), a partir de fontes de João José Reis, confirma a cartografia negra de Salvador do passado escravocrata:

(...) Esta impressão é confirmada pelo censo de 1775. Neste computo, dos 32.253 habitantes de Salvador, $36 \%$ era brancos, a população de cor representada nada menos do que $64 \%$ dos moradores da cidade. Esta população estava dividida segundo sua condição jurídica e as matrizes "cromáticas". Era cerca de 4.207 mulatos livres (12\%), 3.630 negros livres (10,4\%), e 14.696 escravos negros e mulatos (41\%) (REGINALDO, 20011; 103).

Durante 388 anos, Salvador abasteceu o mercado mercantil do Brasil e do mundo, por intermédio da produção, inicialmente, da cana de açúcar, do fumo e posteriormente, todo tipo de alimentos, materiais que eram produzidos no Recôncavo e nas urbes da Bahia.

Além da produção de gêneros alimentícios, a principal mercadoria foi a mão de obra africana e afro-brasileira, que migrou dos portos da Bahia em direção às regiões do sudeste e sul. Após a descoberta do ouro das Minas Gerais e, em 1845, com o fim do tráfico de escravos no mundo, internamente, milhares de africanos escravizados migraram para compor novos territórios da economia colonial. A economia, baseada na cana de açúcar, do ouro e do café mudou profundamente o país.

Os dados da tabela abaixo representam, de um lado, a herança do trabalho escravo e, de outro lado, a história do século XX e o momento atual, da sociedade do meio técnico científico informacional.

As urbes de Serrano do Maranhão ${ }^{3}(93,35 \%)$ e Bacuritiba $(92,16)$ estão entre as dez cidades com maior participação negra, ambas, estão localizadas fora da região

\footnotetext{
${ }^{3}$ Serrano do Maranhão está a 111 km e Bacuritiba a 365 km da Capital, São Luiz. Ambas apresentam IDH baixo.
} 
metropolitana de São Luiz. As duas cidades têm a economia voltada para a produção agrícola; a população ocupa, em sua maioria, o espaço predominantemente rural.

Na Bahia, principalmente na região do Recôncavo Baiano, estão as oito cidades que reúnem os percentuais mais altos de população negra; as urbes de Pedrão (92,8\%), São Gonçalo dos Campos (92,47\%), Antonio Cardoso (92,72\%), São Francisco do Conde (91,86\%), Aramari (91,71\%), Conceição de Feira (91,61\%), Irará $(91,3 \%)$ e Amélia Rodrigues (91,16\%).

Conforme os dados da tabela 1 acima, de 2000 a 2010, o Brasil apresentou mais de $50 \%$ de população classificada como negra. Nas cidades negras, que contemplam os percentuais mais altos, de $91 \%$ a $93,35 \%$, esta geografia corresponde a herança dos 388 anos da sociedade escravocrata e os 132 anos do capitalismo do meio técnico científico informacional.

O crescimento da taxa relativa e absoluta de pessoas negras no país e nas cidades, deve-se ao contínuo processo de enfrentamento aos cenários da segregação racial e das desigualdades que são mais emblemáticas no universo dessa população. $O$ enfrentamento, inicialmente, está associado ao histórico da produção das identidades negras; de superação do mito da igualdade racial entre brancos e negros (OLIVEIRA, 2016; OLIVEIRA (b), 2015).

Nos últimos 132 anos, o racismo e a segregação seguem algumas características: em geral, a população negra ocupa os territórios mais vulneráveis, da pobreza e de menor urbanização; segue o critério da linha de cor, as pessoas mais escuras estão concentradas nas áreas pobres e de menor desenvolvimento e/ou nas áreas centrais e intermediárias, porém, se localizam na base da hierarquia socioeconômica e política (OLIVEIRA, 2013; 2015; 2016).

A segregação racial está presente nos espaços urbanos e rurais, em ambos, a população negra está sobrerepresentada nos territórios de menor valorização e oportunidades de uso e acesso ao ambiente construído de consumo coletivo público e privado.

O quadro conceitual da segregação racial está centrado nas referências que desenvolvi nos últimos anos (OLIVEIRA, 2013; 2016; 2017; 2018), referente aos espaços urbano e rural, sobretudo do urbano. Dentre as características que reforçam o cenário da segregação racial nos últimos 150 anos, destaco aqui três características: a 
primeira, a lei de terras de 1850 , que inviabilizou a população negra de se tornar empreendedora nas proximidades da abolição e posteriormente; a segunda, desde as primeiras décadas do século $\mathrm{XX}$, a política antinegro reservou aos mais escuros os últimos lugares das cidades, como os morros, as roças distantes, as favelas e as primeiras periferias; a terceira, paulatinamente, a geografia das cidades foi sendo estabelecida conforme a cor da pele e a condição socioeconômica, como São Paulo, Rio de Janeiro, Salvador e nas cidades negras, conforme a relação da tabela 1 acima (OLIVEIRA, 2016; COSTA, 1995).

A segregação nas áreas rurais deve-se, inicialmente, aos trâmites da escravidão e seu legado, por exemplo, as forças escravocratas agiram com o apoio da lei para impedir qualquer possibilidade da população negra receber bases materiais e subjetivas para se desenvolver nas proximidades da abolição com a posse da terra e da habitação. Nas cidades negras destacadas acima, as grandes áreas voltadas para a agricultora não estão nas mãos da massa negra. Do pós abolição aos dias de hoje, o mercado da terra e da habitação permanece nas mãos dos grupos de maior poder aquisitivo e branco.

A lei de terras de 1850 e as políticas antinegro estabelecidas no decorrer do século XX, em geral, perfazem os impedimentos que caracterizam a segregação racial no Brasil, sobretudo o contexto das áreas rurais, como os cenários das pequenas e médias cidades.

Nas cidades que compõem o Recôncavo da Bahia, tenho observado que a população negra das áreas urbana e rural, ocupa a base da hierarquia socioeconômica. $\mathrm{Na}$ zona rural, homens e mulheres negras, desenvolvem a agricultura familiar, são remanescentes de quilombos, são moradores que prestam serviços no urbano, enfim, as extensas áreas não são de propriedade da população negra.

A leitura da tabela 2 abaixo, contempla a contextualização da sobrerepresentação e subrepresentação nos espaços urbano e rural entre brancos e negros. Em 2010, o Brasil apresentava uma população de 29.829.995 habitantes vivendo em áreas rurais, 15,36\% da população nacional. A população branca vivendo em área rural corresponde a 10.839.117 habitantes, em dados relativos são 36,33\%. Entre os negros, eles alcançam a soma de 18.205.901 habitantes, representam 61,03\% de indivíduos no espaço rural. A população negra é maioria no universo da área rural, no entanto, esta expressão demográfica não reflete no exercício de poder socioeconômico e político. 
Nas palavras de Milton Santos (1993), a urbanização brasileira na história do século XX obteve transformações rápidas, sem contemplar o quadro de planejamento urbano da sociedade urbano industrial, das pequenas, médias e grandes cidades. Segundo Santos (1993), em 1940 a taxa de urbanização era de 26,35\%, posteriormente, em 1980, alcançou 68,86\% da população. Hoje, conforme dados do censo demográfico de 2010, 84,36\% da população está fixada em áreas urbanas.

Nas zonas rurais, a população que vive nesse ambiente corresponde a 15,36\%. De 1940 a 2010, a sociedade brasileira alterou rapidamente a relação entre os espaços urbano e rural. A urbanização seguiu a regra do capitalismo urbano e industrial, significou a produção de cidades e espaços urbanos espoliados, com ritmos de crescimento cada vez mais rápidos com a edificação das periferias, favelas e extensos territórios perfazendo as cidades "fora da lei” (ROLNIK, 1997; KOWARICK, 1993).

Em um intervalo de 60 anos, conforme as ideias de Rolnik (1997), Santos (1993) e Kowarick (1993), as cidades no Brasil, sobretudo as metrópoles e urbes do capitalismo nacional e internacional, retratam o aprofundamento das distâncias entre brancos e negros na geografia das cidades. A segregação da população negra vem crescendo sempre em direção aos territórios da pobreza e da vulnerabilidade.

Nas cidades de Serrano do Maranhão e Bacuritiba, a população que vive em áreas rurais é proporcionalmente superior aos habitantes que vivem no território urbano. Mais de $50 \%$ da população destas duas pequenas cidades perfazem suas atividades sociais na zona rural. Mas é inegável que o crescimento da sociedade urbana, de forma muito rápida e sem o planejamento, refletiu com grande impacto nos quadros sociais da população brasileira.

Santos (1993) em suas observações sobre a urbanização brasileira, traz indicações de que a sociedade atual representa o cenário do urbano e do agrícola, ao invés do urbano e rural. Esta consideração é delineada com a seguinte interpretação: em razão do desenvolvimento do capitalismo local, regional, nacional e global, a produção se passa em áreas agrícolas e urbanas; as regiões agrícolas (e não rurais) contem cidades, as regiões urbanas contem atividades rurais. A produção do capitalismo nacional e global, concentrou-se na produção de gêneros agrícolas; a produção de soja, milho, a bovinocultura, a avicultura e demais gêneros alimentícios, tendo como objetivo o mercado internacional. 
As cidades pequenas e médias no Brasil, sobretudo as cidades negras, provavelmente, viverão a transformação dos espaços urbano e rural, com a sobreposição da área agrícola. Milton Santos em diálogo com Michel Serres, descreve o seguinte quadro sobre as transformações do espaço e do território: nossa relação com o mundo mudou; antes, ele era local-local; agora é local-global (SANTOS, 2006).

Tabela 2. Distribuição de População Brasileira classificada por cor raça, urbano e rural das Dez Cidades com maior participação negra, 2010

\begin{tabular}{|c|c|c|c|c|c|c|c|c|c|}
\hline \multirow{3}{*}{$\begin{array}{c}\text { Brasil e } \\
\text { Município }\end{array}$} & \multicolumn{9}{|c|}{ Cor ou raça x Situação do domicílio } \\
\hline & \multicolumn{3}{|c|}{ Total } & \multicolumn{3}{|c|}{ Branca } & \multirow{2}{*}{$\begin{array}{c}\text { Negra } \\
\text { Total }\end{array}$} & \multirow[b]{2}{*}{ Urbana } & \multirow[b]{2}{*}{ Rural } \\
\hline & Total & Urbana & Rural & Total & Urbana & Rural & & & \\
\hline Brasil & 190755799 & 160925804 & 29829995 & 91051646 & 80212529 & 10839117 & 96795294 & 78589393 & 18205901 \\
\hline $\begin{array}{c}\text { Serrano } \\
\text { do } \\
\text { Maranhão } \\
\text { (MA) }\end{array}$ & 10940 & 4227 & 6713 & 470 & 212 & 258 & 10367 & 3981 & 6386 \\
\hline $\begin{array}{c}\text { Bacuritub } \\
\text { a (MA) }\end{array}$ & 5293 & 1424 & 3869 & 448 & 173 & 275 & 4768 & 1216 & 3552 \\
\hline $\begin{array}{c}\text { Pedrão } \\
\text { (BA) }\end{array}$ & 6876 & 1716 & 5160 & 400 & 99 & 301 & 6363 & 1580 & 4783 \\
\hline $\begin{array}{c}\text { São } \\
\text { Gonçalo } \\
\text { dos } \\
\text { Campos } \\
\text { (BA) }\end{array}$ & 33283 & 16505 & 16778 & 2475 & 1226 & 1249 & 30597 & 15153 & 15444 \\
\hline $\begin{array}{c}\text { Antônio } \\
\text { Cardoso } \\
\text { (BA) }\end{array}$ & 11554 & 3225 & 8329 & 859 & 390 & 469 & 10591 & 2792 & 7799 \\
\hline $\begin{array}{c}\text { São } \\
\text { Francisco } \\
\text { do Conde } \\
\text { (BA) }\end{array}$ & 33183 & 27391 & 5792 & 2239 & 1863 & 376 & 30156 & 24834 & 5322 \\
\hline $\begin{array}{l}\text { Aramari } \\
\text { (BA) }\end{array}$ & 10036 & 5125 & 4911 & 750 & 521 & 229 & 9189 & 4527 & 4662 \\
\hline $\begin{array}{c}\text { Conceição } \\
\text { da Feira } \\
\text { (BA) }\end{array}$ & 20391 & 13137 & 7254 & 1746 & 1219 & 527 & 18353 & 11695 & 6658 \\
\hline Irará (BA) & 27466 & 11246 & 16220 & 2161 & 1197 & 964 & 24994 & 9953 & 15041 \\
\hline $\begin{array}{l}\text { Amélia } \\
\text { Rodrigues } \\
\text { (BA) }\end{array}$ & 25190 & 19957 & 5233 & 2134 & 1776 & 358 & 22874 & 18027 & 4847 \\
\hline
\end{tabular}

Fonte: Banco SIDRA, Censo Demográfico do IBGE, 2010. 
Tabela 3. Rendimento Nominal Médio de negros e brancos nas dez cidades com maior participação da população negra

\begin{tabular}{|c|c|c|c|c|}
\hline Brasil/Município & Total & Branco & Negra & $\begin{array}{l}\text { Diferença entre } \\
\text { Negros e Brancos }\end{array}$ \\
\hline Brasil & $1.344,70$ & 1705,84 & 939,06 & $55 \%$ \\
\hline $\begin{array}{c}\text { Bacuritiba (MA) } \\
\text { Serrano do } \\
\text { Maranhão (MA) }\end{array}$ & 421,71 & 365,78 & 389,13 & $0,6 \%$ \\
\hline Pedrão (BA) & 436,40 & 263,87 & 367,33 & 61,25 \\
\hline $\begin{array}{c}\text { S.Gonçalo dos } \\
\text { Campos (BA) }\end{array}$ & 737,28 & 382,98 & 430,97 & $88 \%$ \\
\hline $\begin{array}{c}\text { Antonio Cardoso } \\
\text { (BA) }\end{array}$ & 427,67 & $2.165,20$ & 627,57 & $28,89 \%$ \\
\hline $\begin{array}{c}\text { S.Francisco do } \\
\text { Conde (BA) }\end{array}$ & 875,22 & 489,03 & 427,82 & $87 \%$ \\
\hline $\begin{array}{c}\text { Aramari (BA) } \\
\text { Conceição de Feira } \\
\text { (BA) }\end{array}$ & 650,66 & 740,45 & 862,23 & $95,12 \%$ \\
\hline $\begin{array}{c}\text { Irará(BA) } \\
\text { Amélia Rodrigues }\end{array}$ & 463,76 & 647,24 & 623,86 & $84,26 \%$ \\
\hline (BA) & 679,03 & 899,34 & 419,98 & $96,86 \%$ \\
\hline
\end{tabular}

Fonte: Banco SIDRA, Censo Demográfico do IBGE, 2010.

A relação local-global tem se manifestado cada vez mais fragilizando os grupos de menor poder aquisitivo e os vulneráveis, nos espaços urbano e rural. Nas pequenas e médias cidades do Recôncavo da Bahia e da região de Feira de Santana, o urbano está inscrito em tudo, em particular nas cidades de São Gonçalo dos Campos, São Francisco do Conde, Aramari, Conceição de Feira e Amélia Rodrigues. No rural, são as cidades de Pedrão, Antônio Cardoso e Irará que correspondem ao maior número de habitantes. Nas cidades do Recôncavo, a região agrícola tem alterado a relação entre o urbano e o rural.

As informações das tabelas 1 e 2, parcialmente, proporcionaram uma breve leitura das pequenas e médias cidades negras. Até o momento, apresentei dados substanciais para delinear o cenário da segregação racial nas cidades com elevados percentuais da população negra. A tabela 3 acima, referente ao rendimento nominal médio entre brancos e negros no Brasil e nas cidades observadas, irá proporcionar avançar na problematização.

Conforme a tabela 3 acima, o rendimento médio do brasileiro corresponde a $\mathrm{R} \$$ 1.344,70 no território nacional. Quando o rendimento é classificado entre brancos e negros no território nacional, o quadro da segregação racial ganha destaque: a força de 
trabalho negra recebe aproximadamente $\mathrm{R} \$ 939,06$, corresponde a 55\% dos ganhos da população branca, que alcança $\mathrm{R} \$ 1.705,84$.

Nas pequenas e médias cidades com maioria negra, os rendimentos da população branca são superiores aos ganhos da população negra. Entre as dez cidades, em apenas três, o rendimento da força de trabalho negro é superior, mas é uma situação de superioridade diante de muita pobreza. Em Bacuritiba, o rendimento nominal médio da população negra é superior em apenas $0,6 \%$ ao rendimento dos brancos.

Os ganhos de brancos e negros, em média, são inferiores a um salário mínimo que corresponde a $\mathrm{R} \$ 1.045,00$. Em sete cidades, homens e mulheres negras recebem ganhos inferiores aos brancos. A grande distância de rendimentos está localizada em São Gonçalo dos Campos, nessa urbe a população negra recebe aproximadamente $28 \%$ dos ganhos da população branca.

Nas regiões norte, nordeste, sudeste, sul e centro oeste, o rendimento nominal médio da população branca é superior aos ganhos da força de trabalho negra. Nas observações do quadro das 5.565 cidades, quanto aos ganhos entre brancos e negros, em apenas 149 urbes, a população negra supera os ganhos da população branca. Reitero as considerações acima, nas cidades em que a população negra ultrapassa o rendimento da população branca, a renda média nos municípios quase não se aproxima de um salário mínimo.

Nos cenários urbano e rural, além da sobrerepresentação socioeconômica, a população branca leva vantagens nas oportunidades quando está em disputa com o negro. A vantagem está localizada em contextos da hierarquia que mantem benefícios para este grupo: a meritocracia que beneficia quem tem as oportunidades em capital social, econômico e político; a segregação racial beneficia e traz vantagens para o grupo étnico racial que usufrui do ambiente construído; os valores da branquitude reforçam as vantagens socioeconômica e política da população branca.

Nas cidades negras, os poucos habitantes brancos não ficam nos últimos lugares da hierarquia de poder, por exemplo: os 400 habitantes brancos da cidade de Pedrão, recebem 88\% dos rendimentos dos negros; a urbe de São Francisco do Conde está 131 km de distância de Salvador, são 2239 habitantes brancos que recebem, em média, valores acima dos mais de 30.000 habitantes negros. 
No universo das grandes cidades, a população negra recebe entre $40 \%$ e $60 \%$ dos rendimentos da população branca. Entre as pequenas e médias cidades, mesmo estando em maior número, a população negra recebe os menores rendimentos.

A cartografia das cidades brasileiras compreende um cenário complexo, em princípio, é uma estrutura que relaciona classe social, gênero e etnia raça. Os dados acima reforçam a interpretação das desigualdades socioeconômicas e étnico raciais. Frente à perspectiva de gênero, os estudos de Antonia dos Santos Garcia $(2013$; 2007) e Oliveira (208; 2016), ambos abordam a situação das mulheres negras nos espaços das cidades de São Paulo e Salvador.

Na ex-capital federal, Salvador ${ }^{4}$, a estrutura que mantem as mulheres negras nos últimos lugares está baseada em diferenças de classe social, gênero e etnia raça. Garcia (2013) destaca que na capital soteropolitana, existem diferenças espaciais entre o subúrbio e as áreas valorizadas (nos bairros da Graça, Ondina, Barra, Pituba, Canela, Iguatemi, Itaigara, etc).

Garcia apresenta um quadro histórico e contemporâneo importante diante do cenário da hierarquia das desigualdades. Nas áreas mais pobres e de menor urbanização, as mulheres brancas levam vantagens materiais e simbólicas em relação às negras. Nos bairros e regiões de maior concentração de renda e urbanização, as desigualdades de classe social, gênero e etnia raça, gradualmente, tendem a se apresentar superior.

As desigualdades, da forma que ela se apresenta na capital da Bahia, hierarquiza homens e mulheres, brancos e negros na estrutura da sociedade. Oliveira (2016), na capital paulistana também obteve a mesma cartografia das desigualdades. Na estrutura de poder econômico, primeiro comparece o homem branco, em seguida a mulher branca, posteriormente o homem negro e por último, a mulher negra.

Nas cidades negras, tendo como referências as informações de Garcia e Oliveira, as mulheres negras estão na base da hierarquia das desigualdades de classe social, gênero e etnia raça. Conforme a tabela acima, das dez urbes negras, em sete, o rendimento da população negra é inferior aos ganhos dos brancos. Provavelmente, mesmo nas cidades negras, a força de trabalho das mulheres negras ocupa os últimos

\footnotetext{
${ }^{4}$ Dentre as 100 cidades negras (em \%), Salvador se encontra na $80^{\mathrm{a}}$ posição, com $79,23 \%$ de população negra. É a única capital do país que está entre as urbes com maior participação negra, em dados relativos. A capital soteropolitana está entre 100 maiores urbes do país, em dados relativos e absolutos.
} 
lugares, elas estão distribuídas nas atividades de informalidade, prestação de serviços sem os mínimos direitos e tudo isso reflete em barreiras e limitações para a população feminina sair dos lugares da pobreza.

Conforme Carlos Hasenbalg (2005), a geografia das raças do passado escravista tem forte influência em nossa contemporaneidade. Nas regiões do país, a hierarquia das desigualdades está estruturada em relações e características que mantem a população branca sobrerepresentada nas classes média e alta e nos espaços e territórios de intensa urbanização e desenvolvimento, tendo como retrato social, por exemplo, a geografia da casa grande e senzala. Nos dias de hoje, conforme as ideias de Hasenbalg, as cidades negras do Nordeste, tem como justificativa a segregação da população negra nas áreas e territórios de menor desenvolvimento em relação ao sudeste e sul, que apresentam maior desenvolvimento socioeconômico e político.

A educação de nível superior é um percurso para as mulheres e jovens negras superarem o bloqueio histórico. Gradativamente, é provável que as conquistas das mulheres negras venham a incomodar os benefícios que mantem a hierarquia sob o domínio branco, masculino e das classes sociais de maior poder aquisitivo.

\section{O CHÃO DO RECÔNCAVO}

O canto dos homens e mulheres negras está nas cidades negras, pequenas, médias e grandes da realidade nacional. Nas urbes negras, a musicalidade está inscrita no chão com o samba, o axé music, o funk, o hip hop, a música popular brasileira, enfim, as expressões negras que edificaram a cultura brasileira e as identidades nacionais (ORTIZ, 2002; CHAUI, 2005).

A música, as danças, as artes da cultura negra foram também edificando as cidades, vilas, igrejas, terreiros de umbanda e candomblé, praças e os espaços públicos e privados. O canto da cidade, interpretada por Daniela Mercury, destaca a capital soteropolitana como um território rico, diverso e de muita efervescência social e cultural, no entanto, nas cidades de maioria negra (em dados relativos e absolutos) como Salvador, Rio de Janeiro, São Paulo, Belo Horizonte, enfim, a hierarquia das desigualdades impede que o ecoar dos cantos, das danças e histórias negras transformem radicalmente os espaços em territórios de liberdade e cidadania para todos. 
Nos territórios do Brasil e da diáspora africana, a política antinegro não impediu que parte da civilização humana se inscrevesse na cultura e na história das cidades. Nas cidades do Recôncavo, Salvador, São Paulo, Rio de Janeiro, o universo do samba, do funk, do rap e da música negra está nas ruas, praças, avenidas, no dia a dia dos territórios negros enfrentando o racismo e a segregação. Nas cidades negras e da diáspora, os cantos negros edificaram quase tudo durante os 388 anos de escravismo e no decorrer do século XX.

A letra da música bluessman, de Baco Exu do Blues, rapper soteropolitano, provavelmente, retrata a história da cultura africana e afro-brasileira na edificação das culturas e identidades.

"Eu sou o primeiro ritmo a formar pretos ricos O primeiro ritmo que tornou pretos livres Anel no dedo em cada um dos cinco Vento na minha cara, eu me sinto vivo A partir de agora considero tudo blues

O samba é blues, o rock é blues, o jazz é blues O funk é blues, o soul é blues, eu sou Exu do Blues

Tudo que quando era preto era do demônio E depois virou branco e foi aceito, eu vou chamar de blues

É isso, entenda Jesus é blues Falei mermo (...)"

A música acima retrata outras realidades, mas aqui, reitero que o canto da população negra, mesmo com as ininterruptas forças da política antinegro, vêm mantendo parte de sua força motriz viva, reluzente para si, seus semelhantes e às diferenças.

As culturas e artes negras estão no chão das cidades, sociedades e estados, aqui, na sociedade brasileira, o canto, a dança, a poesia e as expressões negras estão nas cidades negras, nos territórios negros e nos espaços onde o racismo e a segregação se manifestam.

As religiões negras do Brasil e da diáspora, como o catolicismo negro, o candomblé e a umbanda, o gospel e o protestantismo afro-americano, sobretudo o candomblé, o canto está em tudo, desde o nascimento, a preparação do alimento, a celebração dos orixás, está inscrito nos quatro elementos da terra, ar, água e fogo. O canto da população negra no Brasil e na diáspora, é uma produção que tem como 
natureza a relação do cotidiano com os aspectos étnicos raciais, a memória e os momentos de grande superação, como foi a resistência de quase quatro séculos de escravismo.

Nas urbes da Bahia, Rio de Janeiro e São Paulo, nas grandes metrópoles brasileiras a manifestação do canto, de origem popular que mais se espalhou é o samba (MOURA, 1983). O samba é um canto, uma manifestação hegemonicamente brasileira, que se inscreveu em todas as cidades do país, muito antes de ser incorporado como parte das identidades e da cultura brasileira. Antes de conquistar o lugar de cultura nacional, o samba e inúmeras manifestações culturais negras, durante o escravismo e após a abolição, como o candomblé e a umbanda, foram e continuam sendo perseguidos. No momento atual, a perseguição acontece na perspectiva das religiões, por exemplo, o racismo religioso praticado por indivíduos e setores das religiões católica e protestante com o candomblé e a umbanda.

Daniela Mercury e Baco Exu do Blues, mesmo manifestando diferentes concepções culturais, acredito que compartilham das mesmas considerações; nas cidades negras e da diáspora, o som dos negros se interiorizou na alma das cidades.

Nas tabelas 1, 2 e 3, retratei o cenário histórico e atual das cidades negras do Brasil, parte das informações, possibilitou interpretar que nas urbes pequenas e médias, a hierarquia das desigualdades se apresenta de forma diversa: estão localizadas em territórios que no passado foram palco e sede da colonização e do capital mercantil; as cidades de Salvador, Recôncavo e os territórios que utilizaram fartamente da força de trabalho dos escravizados, nos dias de hoje, os descendentes se destacam na geografia das urbes, direta e indiretamente; no passado e nos dias de hoje, a força de trabalho negra mantem as bases materiais e subjetivas das cidades, portanto, é preciso compreender e estabelecer diálogos para fins de fazer com que as ideias e os lugares, além de serem centrais nos "cantos" das cidades, sejam realmente retratados no pensamentos urbanístico e das políticas públicas da cidade.

A imagem abaixo (mapa dos quilombos), confirma parte da interpretação construída no decorrer do texto, as cidades de Salvador, Recôncavo e a região da Chapada, no passado setecentista até o final da abolição, diante da violência e do genocídio da sociedade escravista, a população negra buscou a produção de espaços e territórios para além da cidade formal e da lei. 


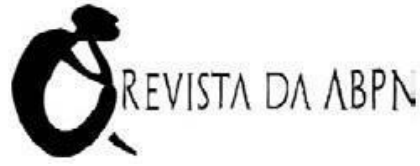

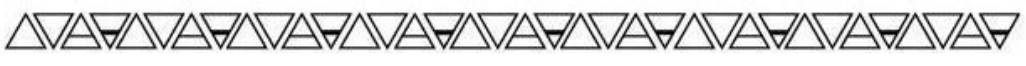

Mapa 1. Mapa dos Quilombos no Estado da Bahia, séculos XVIII e XIX.

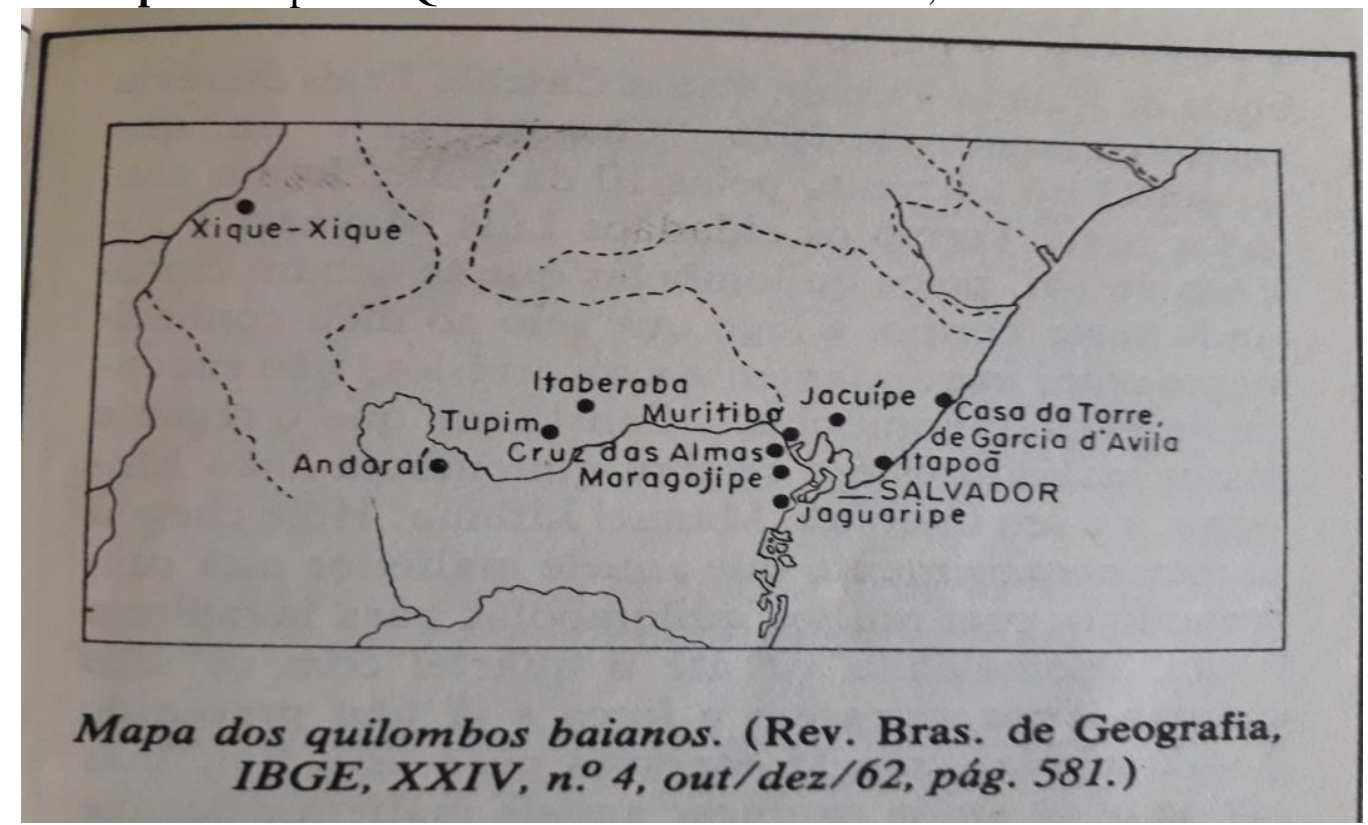

Fonte: Clovis Moura (1987). Os Quilombos e a rebelião negra

João José Reis, Lucilene Reginaldo (2011) e Edmar Ferreira Santos (2009) trazem importantes informações sobre o passado das pequenas, médias e grandes cidades da atualidade. Reis destaca que nos idos de 1735, a população negra (escrava, livre e forro) já alcançava mais de $60 \%$ da população de Salvador, nas imediações, como Santo Amaro, São Gonçalo e Cachoeira, a população negra se destacava nas ruas e espaços públicos, igual e/ou acima do que a ex-capital federal representava.

Durante os 388 anos de sociedade escravocrata, os diferentes grupos étnicos nos espaços urbano e rural foram perfazendo pequenas revoltas, motins e conflitos nos espaços das cidades brasileiras. Dentre as revoltas e enfrentamentos, a Revolta dos Malês (1835) e a Revolta de Búzios (1798) foram movimentos e organizações arquitetadas por quilombolas, africanos livres, escravos e forros, que empreenderam forças e organização política em torno da luta por liberdade.

As cidades de Salvador e da região do Recôncavo, no decorrer dos 388 anos, exerceram papéis importantes no contexto local e nacional. O coração da economia 
estava localizado na região de Santo Amaro, Cachoeira, São Gonçalo, São Francisco do Conde, enfim, no território do Recôncavo: a produção da economia girava em torno da cana de açúcar, do fumo e dos mais diversos gêneros alimentícios e os produtos que escoavam, desde o sul do estado e as regiões do Sertão e Chapada para abastecer a capital e o mundo. O centro econômico de produtos estava localizado nas cidades do Recôncavo, que exerciam, por intermédio do trabalho escravizado, a principal economia do país nos séculos XVII, XVIII e XIX (REIS, 2000).

Se o Recôncavo era o centro econômico de produção, Salvador era a sede do poder político e, em especial, onde estava localizada a força e os territórios que buscavam subverter as ordens e leis da cidade colonial. A ex-capital federal abrigava a maioria dos libertos africanos, os quais forneciam infraestrutura material e quadro político para a resistência, tendo em vista planejamento e mobilização, de articulação geográfica dos libertos e escravizados.

Por muito pouco, a Revolta dos Malês não mudou a história da Bahia e do Brasil, sobretudo da hierarquia das desigualdades entre brancos e negros em nossa atualidade. O Levante dos Malês, teve à frente africanos islamizados de diferentes grupos étnicos da Costa da África. Reis retrata o desfecho estabelecido pela colonização portuguesa diante dos insubordinados africanos e afro-brasileiros na cidade de Salvador, segue abaixo:

Seus nomes e memória tornados malditos até a terceira geração. Os corpos dos quatro enforcados foram exquartejados e expostos nos lugares públicos, à época intensamente frequentados. A cabeça de Luiz Dantas ficou espetada no campo do Dique do Desterro. A de Manuel Faustino, no cruzeiro de São Francisco. A de João de Deus, na Rua Direita do Palácio, atual Rua Chile. A cabeça e as mãos de Luiz Gonzaga das Virgens ficaram pregadas na forca exibida na Praça da Piedade (JOÃO JOSÉ REIS).

A prática da violência e genocídio dos corpos negros, conforme descrição acima, aconteceu nos momentos do trabalho, nas revoltas e rebeliões e, sobretudo em quase quatro séculos de escravismo brasileiro. Parte do desfecho da Revolta dos Malês, da Revolta de Búzios, da Balaiada e outras que libertos, quilombolas e escravizados estiveram na articulação, talvez se explique nas milhares de mortes da população negra que se sucederam no século XX e no momento atual, como os oitenta tiros que um homem negro, músico e pai de família levou por estar no lugar errado e ser negro, as 
mortes brutais de jovens negros na Favela Paraisópolis, em São Paulo, a morte da menina Ághata e do adolescente negro, João Pedro, de 14 anos, morto em sua própria casa, de Miguel, assassinado aos 5 anos de idade pelo racismo à brasileira, todos os quatro casos comprovam o genocídio da população negra sob a força do Estado, por intermédio da polícia militar.

A violência está na fundação da sociedade brasileira e da pós-abolição aos dias de hoje, ela se faz presente diante da geografia das desigualdades entre brancos e negros.

O canto bluessman, poesia rítmica e crítica de Baco Exu do Blues, também tem a referida contextualização, a subjetividade negra teve que ser plantada na terra, no chão das cidades brasileiras e da diáspora para se tornar resistente e continuar ecoando nas vozes daqueles que buscam subverter a ordem e a lei da hierarquia das desigualdades históricas.

A necropolítica no Brasil, está na história dos 500 anos. Está na constituição das cidades pequenas, médias e grandes. Salvador e as urbes do Recôncavo, reservam em seus territórios o canto pela liberdade que ecoa em todas as direções da cidade. Nas urbes de Salvador e de suas cercanias, os sons do passado agitam e movimentam a busca pela superação da hierarquia das desigualdades.

Lucilene Reginaldo (2011) em trabalho intitulado "Os Rosários dos Angolas Irmandades de Africanos e crioulos na Bahia setecentistas", revela outro cenário da cidade de Salvador e das urbes do Recôncavo. Segundo a autora, na Bahia setecentista, até o ano de 1763, por ocasião da mudança da capital para o Rio de Janeiro, se estendendo até o ano de 1888, a capital reunia inúmeras igrejas em todas as direções.

Uma marca forte da colonização e urbanização portuguesa, diante do protagonismo da economia mercantil nas Américas, a cidade fortaleza se estabeleceu com a necessidade de se defender dos navios estrangeiros que buscavam assumir o lugar dos portugueses em solo brasileiro. Outra importante característica da urbanização de colonização que se espalhou por toda a urbe são as igrejas, edificadas por africanos escravizados.

Conforme o estudo de Reginaldo (2011), a partir da edificação das igrejas em Salvador e a região do Recôncavo, gradativamente, foram fundadas irmandades e confrarias, negras e brancas, sobretudo por escravizados, libertos e forros. As 
irmandades e confrarias negras tinham como objetivos principais: o auxílio aos membros, nos momentos de dificuldades financeiras ou por motivo de doença; a garantia de um funeral cristão para os irmãos e seus familiares; e de maneira especial, a promoção da devoção ao santo padroeiro da confraria.

No passado, desde o setecentista até a abolição, Salvador, o Recôncavo, se estendendo a Ilhéus, chegaram a reservar em seus territórios entre mais ou menos 40 irmandades negras; adotadas pela população de cor, a devoção aos santos, Santa Ifigênia, São Elesbão, Santo Rei Baltazar, Santo Antônio de Categerona. Na capital da Bahia, as devoções mais populares dos cativos e forros foram as de Nossa Senhora do Rosário e São Benedito. Nos idos de 1835, foi fundada na capela de Nossa Senhora da Penha de Itapagipe uma irmandade de Pretos, dedicada ao culto do Rosário de Nossa Senhora (REGINALDO, 2011).

O Recôncavo, parcialmente, também obteve a organização e protagonismo de irmandades e confrarias negras. Em 1837, a vila de Nossa Senhora do Rosário do Porto da Cachoeira foi elevada à categoria de cidade reconhecida por sua participação nas disputas emancipatórias ocorridas na Bahia. À época, a pequena cidade já se destacava como o mais importante centro de negócios e comércio do Recôncavo. Portanto, a religiosidade em devoção a Nossa Senhora do Rosário é pedra fundante de Cachoeira.

Segundo Edmar Ferreira Santos (2009), Lucilene Reginaldo (2011) e Adriana Carvalho Silva (2015), as cidades de Salvador, Cachoeira e São Gonçalo dos Campos, reservam em seus territórios, as irmandades de Nossa Senhora do Rosário dos Homens Pretos. Após o Concílio Vaticano II, o documento estabeleceu o fim da devoção aos santos e santas, causando um grande impacto no catolicismo da América Latina, em especial, nas irmandades negras.

Conforme Antônia Quintão (2002), a organização das irmandades negras, sobretudo as devoções a São Benedito e Nossa Senhora do Rosário, foi um processo de territorialização negra em inúmeras cidades brasileiras; nas urbes do Rio de Janeiro, São Paulo, Jundiaí, Campinas, Santos, Salvador, Cachoeira, em diferentes regiões e localidades do país.

Para Edmar Ferreira Santos (2009), Cachoeira, além de ser fundamental na economia colonial, juntamente com Salvador, reserva em seu território as manifestações religiosas de matriz africana e afro-brasileira. As religiões candomblé e umbanda, 
historicamente, estão inscritas nas cidades de Salvador, Cachoeira, nas regiões do Recôncavo, Feira de Santana e nos territórios do país, sobretudo nas urbes em que a população negra se faz presente.

Santos (2009) destaca que Cachoeira foi caracterizada como a cidade do "feitiço" ou a cidade da "macumba". O autor, em suas observações sobre o poder dos candomblés, destaca a perseguição da imprensa local, do poder público e da força policial nas três primeiras décadas do século XX. Diferente da geografia de Salvador, a ocupação dos espaços pelos terreiros de candomblé em Cachoeira, o percurso seguia em direção aos espaços mais distantes, nas áreas rurais, combinando com as necessidades espirituais do contato com áreas verdes, animais, rios e plantas em geral.

O trabalho de Santos (2009) traz importantes contribuições para a contextualização das pequenas e médias cidades. Aqui, destaco a característica religiosa dos terreiros de candomblé e a irmandade religiosa. Uma observação que o autor observou, trata-se da geografia das desigualdades entre brancos e negros. Santos, em contato com os pais e mães de santo, ogans, ekedes e o público que vive o universo dos terreiros de Cachoeira, dentre as falas de seus interlocutores, obteve um recorte da segregação racial: quando as casas de candomblés definiram seus lugares na cidade, a escolha pelo lugar, inicialmente, estava associado às condições de silêncio e de estar longe dos olhos dos poderes público e da imprensa. A escolha do território não passava por critérios internos, mas por condições de não ser perseguido e sofrer as sanções das ordens morais e públicas (SANTOS, 2009; 170).

No decorrer do século XX, os terreiros de candomblé e umbanda nas pequenas, médias e grandes cidades, fincaram suas inscrições nos lugares da segregação, distante dos lugares que representam a ordem, a lei e os valores morais (SANTOS, 2009). Em geral, os terreiros de umbanda e candomblé se autossegregaram, em razão da contínua perseguição que eles sofreram no chão das cidades brasileiras. Nas cidades de Salvador, Cachoeira e nas urbes do país, poucas casas de candomblé e umbanda exerceram suas condições culturais e sociais livremente para escolher o lugar no chão das cidades.

Reitero, a interpretação da hierarquia das desigualdades entre brancos e negros é uma característica central para pensar as pequenas e médias cidades no Brasil.

Maria das Candeias dos Santos (2016), Flávia Santana dos Santos (2016), Railma dos Santos Souza (2016) Adriana Carvalho da Silva (2015), produziram 
importantes reflexões em seus trabalhos de mestrado em Ciências Sociais e o Mestrado Profissional em História da África, Afro-brasileira e Culturas Indígenas da UFRB, todos, destacam as particularidades do Recôncavo e Região: na urbe de Feira de Santana, a segunda maior cidade do estado da Bahia, Souza (2016) destaca as comunidades de remanescentes de quilombos da Matinha dos Pretos e Candeal, como importantes referências teórica metodológicas no espaço da cidade negra; Santos (2016) também em Feira de Santana, aborda a Rua Nova, através da resistência de homens e mulheres negras que enfrentaram a segregação racial, ali, edificaram o território negro no chão da cidade, como o terreiro de candomblé, a capoeira, as artes negras, as lideranças femininas negras, o reggae e o espaço da habitação, em geral, reúnem as forças do território negro em espaço urbano; Candeias dos Santos (2016) observa a comunidade remanescente de quilombos em Santo Amaro, por intermédio da abordagem teórica metodológica das lembranças e memórias dos idosos negros sobre o universo do território local e das águas; Carvalho da Silva (2015) se dedica ao contexto da irmandade de Nossa Senhora da Boa Morte em São Gonçalo dos Campos, município vizinho de Cachoeira, retratando a história da cidade e o duplo pertencimento religioso, o catolicismo negro e o candomblé; as experiências teórica metodológicas são importantes referências que justificam a centralidade do passado e de nossa contemporaneidade da população negra nas pequenas e médias cidades do Recôncavo da Bahia ${ }^{5}$.

De 2006 até o momento atual, a Universidade Federal do Recôncavo da Bahia UFRB, instalada com seus campis nos municípios de Santo Amaro, Cruz das Almas, Cachoeira, Feira de Santana, Santo Antônio de Jesus e Amargosa, mudou a dinâmica local e regional das pequenas e médias cidades do Recôncavo e região.

Conforme os comentários acima, o conceito das pequenas e médias cidades é diverso e múltiplo, prova disso é o passado e a contemporaneidade das urbes do Recôncavo. As cidades do Recôncavo, para fins de melhor entendimento histórico e da

\footnotetext{
${ }^{5}$ Segundo dados do Censo Demográfico do IBGE, 2010, as cidades do Recôncavo participam, em dados relativos, com forte representação negra diante do quadro das 100 maiores cidades: Salinas da Margarida, estava na $11^{\mathrm{a}}$ posição $(90,98 \%)$, Governador Mangabeira, estava na $13^{\mathrm{a}}(90,54 \%)$, Itaparica, a $17^{\mathrm{a}}$ $(89,91 \%)$, Saubara, a $18^{\mathrm{a}}$, Jaguaripe, a $20^{\mathrm{a}}(89,62 \%)$, Conceição do Almeida, a $21^{\mathrm{a}}(89,53 \%)$, Santo Amaro, a $22^{\mathrm{a}}(89,39 \%)$, Cabaceiras do Paraguaçu, a $30^{\mathrm{a}}(88,01 \%)$, Cachoeira, a $38^{\mathrm{a}}(89,17 \%)$, Cruz das Almas, a $54^{\mathrm{a}}(84,81 \%)$, Feira de Santana, a $83^{\mathrm{a}}(78,9 \%)$, Santo Antonio de Jesus, a $85^{\mathrm{a}}(76,45 \%)$, Dentre as 100 cidades, a Bahia tem 68 cidades com os percentuais (\%) mais elevados em todo o território nacional.
} 
atualidade, compreende uma complexa produção do espaço artificial e natural, como a importante bacia hidrográfica formada pelos Rios Paraguaçu, Jaguaripe, Rio da Dona e entre outros afluentes, portanto, as pequenas e médias cidades em intersecção às relações étnicas raciais proporcionam entender a segregação racial e as desigualdades das realidades local e nacional com um outro olhar, diferente dos cenários das grandes cidades.

\section{CONSIDERAÇÕES FINAIS}

No decorrer do texto, buscou-se verificar se a segregação étnico-racial e as desigualdades nas pequenas e médias cidades do Brasil são iguais ou diferentes aos grandes centros urbanos.

A partir das interpretações teóricas metodológicas, verificou-se que dentre as cem cidades negras, sessenta e oito estão localizadas no estado da Bahia. Dentre as dez primeiras, duas estão no Estado do Maranhão e oito estão localizadas na Bahia.

Parte deste cenário corrobora para entender que a segregação nas pequenas e médias cidades está, parcialmente, localizada na região nordeste do país.

A segregação nas cidades negras, em especial nas urbes do Recôncavo, é diferente do quadro dos grandes centros urbanos do país. É diferente das urbes de grande porte, porque no chão dessas cidades a herança da sociedade escravocrata e da colonização é muito presente. A população negra ocupa o lugar de sobrerepresentação demográfica, mas não reflete nas posições e lugares de poder socioeconômico e político, inviabilizando a maior participação em espaços estratégicos de desenvolvimento, como o acesso à mobilidade com a entrada e permanência nos cursos de ensino superior nas instituições públicas (UNEB e UFRB), principalmente os curso mais valorizados, como medicina, engenharias e direito.

A população branca das cidades aqui observadas, representa, em média, menos de $8 \%$ da população do universo. Na história do século XX, os $7 \%$ ou $8 \%$ de brancos desse território, se beneficiaram das oportunidades criadas, direta e indiretamente pela segregação étnico racial. No quadro socioeconômico, dentre as dez cidades, em sete o rendimento da população branca é superior aos ganhos da população negra. Portanto, o quadro socioeconômico não passou por transformações profundas, diante das grandes desigualdades que separam brancos e negros. 
As pequenas e médias cidades de Feira de Santana, Cruz das Almas, Cachoeira, Santo Amaro, Santo Antônio de Jesus e Amargosa, no decorrer do século XX, conquistaram espaços importantes na dinâmica urbana e na economia do estado da Bahia. No entanto, o capital social e científico dessas urbes, direta e indiretamente, é mais acessível aos $8 \%$ de brancos do que os $92 \%$ de negros.

As políticas públicas no âmbito das pequenas e médias cidades devem ser diferentes das políticas públicas das grandes metrópoles. No local, a hierarquia das desigualdades está enraizada nas instituições sociais, nas classes sociais e nas diferenças de gênero e étnico raciais.

Nas cidades negras, gradativamente, o som ecoa nos territórios que permanecem em luta, desde os tempos do escravismo até o momento atual, com a execução de jovens negros nas periferias.

O som dos negros está em todos os lugares, nas ruas, avenidas e praças, nas feiras públicas, nos serviços de limpeza da cidade, na força de trabalho como os profissionais da construção civil, as secretárias do lar e todo tipo de trabalho social, enfim, é o som da cultura, do trabalho e de quase tudo que se planta e produz no chão das cidades negras.

$\mathrm{O}$ canto dos negros nas cidades se opõe à necropolítica e à política antinegro. Porque é um canto que historicamente busca iluminar a força, a resistência e a cidade para todos na história do país.

\section{REFERÊNCIAS BIBLIOGRÁFICAS}

CHAUI, Marilena de Souza. Brasil, Mito Fundador e Sociedade autoritária. São Paulo, Editora Fundação Perseu Abramo, 2005.

CORRÊA, José Lobato. As pequenas cidades na confluência do urbano e do rural. GEOUSP, Espaço e Tempo, n. 30, p. 05-12, 2011.

GARCIA, Antonia dos Santos e GARCIA JR., Afrânio Raul. Relações de Gênero, Raça, Classe e identidade Social no Brasil e na França, Salvador, Letra Capital, 2013.

HASENBALG, Carlos. Discriminação e Desigualdades Raciais no Brasil. Belo Horizonte, Editora UFMG, Rio de Janeiro, IUPERJ, 2005.

HENRIQUE, Wendel. A instalação da UFRB, a ação do programa Monumenta e o Turismo Étnico na reestrutura urbana e no cotidiano de Cachoeira BA: notas preliminares da pesquisa. GEotextos, vol. 5, 2009, p.89-112. 
HENRIQUE, Wendel. Cidades universitárias, cidades médias, cidades pequenas: Análises sobre o processo de instalação de novos campi universitários. Revista Espaço Aberto, UFRJ, vol. 5, 2015.

Diferenças e repetições na produção do espaço urbano de cidades pequenas $e$ médias. In: Cidades médias e pequenas: Teorias e conceitos e estudos de caso. Diva Maria F. Lopes e Wendel Henrique (organizadores), Salvador, SEI, 2010.

MAIA, Doralice S. Texto de Apresentação. In: Cidades médias e pequenas: Teorias e conceitos e estudos de caso. Diva Maria F. Lopes e Wendel Henrique (organizadores), Salvador, SEI, 2010.

MARICATO, Ermínia. As ideias fora do lugar e o lugar fora das ideias: Planejamento Urbano no Brasil. In: A Cidade do Pensamento Único - Desmanchando consensos. Petrópolis, Rio de Janeiro, 2002.

MOURA, Clóvis. Os quilombos e a rebelião negra. São Paulo, Editora Brasiliense, 1987.

MOURA, Roberto. Tia Ciata e a pequena África no Rio de Janeiro. Rio de Janeiro, Funarte, 1983.

OLIVEIRA, Reinaldo José de (organizador). A Cidade e o Negro no Brasil: Cidadania e Território. São Paulo, Editora Alameda, 2013.

OLIVEIRA, Reinaldo José de. O Sol nasceu pra todos, a sombra apenas para os brancos: segregação urbana e racial nas cidades brasileiras. In: Dilemas da Raça - Empoderamento e Resistência. São Paulo, Editora Alameda, 2017.

OLIVEIRA, Reinaldo José de. A segregação urbana e racial avançou no Brasil? In: Relações etincorraciais e educação escolar indígena: relatos de pesquisa. Vitória da Conquista, Edições UESB, 2017.

OLIVEIRA, Reinaldo José de. Novos e Antigos cenários da Segregação e das Desigualdades da População Negra em São Paulo. In: Desigualdades urbanas, Segregação, Alteridade e Tensões em Cidades Brasileiras, Maura Pardini Bicudo Véras (organizadora), Judiai, SP, Paco Editorial, 2018.

OLIVEIRA, Reinaldo José de. Territorialidade Negra e Segregação Racial na cidade de São Paulo - A luta por cidadania no século XX. São Paulo, Editora Alameda, 2016.

OLIVEIRA (b), Regina Marques de Souza e OLIVEIRA, Reinaldo José de. Corpos em Cena nas metrópoles Globais: Meninas Negras, Processo de Subjetivação e Cinema. Revista da ABPN, vol.7, número 15, fev de 2015.

ORTIZ, Renato. Cultura Brasileira e Identidade Nacional. São Paulo, Brasiliense, 1985.

QUINTÃO, Antônia Aparecida. Irmandades Negras: outro Espaço de Luta e Resistência (São Paulo: 1970-1890). São Paulo, Annablume, FAPESP, 2002.

REGINALDO, Lucilene. Os Rosário dos Angolas - Irmandades de africanos e crioulos na Bahia setecentista. São Paulo, Editora Alameda, 2011. 
REIS, João José. Identidade e Diversidade Étnicas nas Irmandades Negras no Tempo da Escravidão. Revista Tempo, Rio de Janeiro, 1996, p.7-23.

REIS, João José. O Levante dos Malês: uma interpretação política.

SANTOS, Edmar Ferreira. O Poder dos Candomblés: perseguição e resistência no Recôncavo da Bahia. Salvador, UFRB, 2009.

SANTOS, Flávia Santana. Um Quilombo Urbano chamado Rua Nova. Programa de PósGraduação em História da África, da Diáspora e dos Povos Indígenas, UFRB, 2016.

SANTOS, Jânio. A natureza contraditória da urbanização em um contexto de maior complexidade na produção das cidades brasileiras. In: Cidades médias e pequenas: Teorias e conceitos e estudos de caso. Diva Maria F. Lopes e Wendel Henrique (organizadores), Salvador, SEI, 2010.

SANTOS, Maria das Candeiras dos. Memórias Compartilhadas: Uma Etnogafia sobre a trajetória do idoso e o papel da memória na construção das identidades étnicas nas comunidades quilombolas de São Braz e Cambuta, em Santo Amaro - BA. Dissertação de Mestrado em Ciências Sociais, UFRB, 2016.

SANTOS, Milton. A urbanização brasileira, São Paulo, Editora Hucitec, 1993. $\overline{2006 .}$ A natureza do espaço: Técnica e Tempo - Razão e Emoção. São Paulo, Hucitec,

SILVA, Adriana Carvalho da. Caminhos da Fé: uma etnografia sobre a Irmandade de Nossa Senhora da Boa Morte de São Gonçalo dos Campos BA, Dissertação de Mestrado em Ciências Sociais, UFRB, 2015.

SOUZA, Railma dos Santos. Memória e História Quilombola: Experiência Negra em Matinha dos Pretos e Candeal (Feira de Santana). Dissertação de Mestrado em História do Programa de Pós-Graduação em História da África, da Diáspora e dos Povos Indígenas, UFRB, 2016.

SPOSITO, Maria Encarnação Beltrão. Para Pensar as pequenas e médias cidades brasileiras, Belém, FASE, 2009.

Recebido em: $22 / 09 / 2020$

Aceito em: 30/10/2020 